Acta Technologica Agriculturae 2

Nitra, Slovaca Universitas Agriculturae Nitriae, 2021, pp. 84-91

\title{
PERFORMANCE FEATURES OF TOOTH GEARING IN GEAR HYDRAULIC MACHINES
}

\author{
Yuri V. KULESHKOV', Timofey V. RUDENKO', Mikhailo V. KRASOTA', \\ Miroslav BOŠANSKÝ2*, František TÓTH ${ }^{3}$ \\ ${ }^{1}$ Central Ukrainian National Technical University, Kropyvnytskyi, Ukraine \\ ${ }^{2}$ Slovak University of Technology in Bratislava, Slovakia \\ ${ }^{3}$ Slovak University of Agriculture in Nitra, Slovakia
}

\begin{abstract}
The paper presented determines that the rotation velocities of gears and radii connecting the axes of rotation of the gears with the point of their teeth gearing are not equal with each other. It is explained by the relative slip of involute gear profiles during their rolling. This phenomenon will become a prerequisite for further development of creation of mathematical models in the context of theory of gear hydraulic machines. The models can explain a number of specific phenomena in the operation of gear hydraulic machines, such as pressure and input pulsations, dynamics of hydraulic oil in the cut-off plane, combined torque pulsations in gear hydraulic motors and others.
\end{abstract}

Keywords: gear hydraulic motor; involute tooth gearing; gearing ratio; slip of involute surfaces

Widespread application of gear hydraulic machines in hydraulic systems is a result of simplicity and compactness of their design, reliability, low work content and low manufacturing costs, ease of maintenance, and the possibility of their direct connection to drive mechanisms (Tulík et al., 2017; Kučera and Aleš, 2017; Tkáč et al., 2017). Despite the long history of the development of gear hydraulic machines and a great number of publications in relation to this issue (Casoli et al., 2008; Huang and Chen, 2008), certain features of their operation remain unexplained, indicating that there is still scientific space for further theoretical and experimental studies in order to improve their technical parameters. For example, Wang et al. (2011) addressed the issue of reducing the gear noise and increasing the mechanical efficiency by optimizing their design. Stryczek et al. (2019) investigated the possibilities of application of trochoidal gearing and solved the issue of reducing the contact pressures by optimizing their geometric parameters. Furthermore, Gamez-Montero et al. (2018) developed a method aimed at creating the basic rules in design of trochoidal gear pumps. Ivanovic et al. (2012) built a mathematical model determining the minimum backlash in gearing in relation to the instantaneous gear ratio and examining the influence of geometric parameters of gearing in order to achieve quiet and accurate operation. Zhou et al. (2017) addressed the issue of bearing optimization. |Considering the aforementioned, it is clear that gear pumps are still the subject of research by scientists around the world. Researchers are still unable to explain and determine the causal relationship of multiple operation features of gear hydraulic machines, including formation of and changes in the geometric parameters of the cut-off plane, decrease in the displacement in contrast to expected value, the causes of the inlet pulsation and pressure, and the pulsating change in the gear hydraulic motor torque.

Presented paper describes a theoretical contribution aiming to further develop the mathematical models of movement of hydraulic oils in the pump body in relation to the pulsation of pressure and oil supply, and changes in bearing load.

\section{Material and methods}

The research results presented can become the basis for further development of the theory of gear hydraulic machines. The main directions of these theoretical studies are as follows:

- study of the input nature taking into account the aforementioned features in the operation of gear hydraulic machines;

- study of the features of changes in the cut-off plane and hydrodynamic processes occurring in it;

- study of the inlet pulsation and pressure;

- study of the load dynamics in pump bearings and motor;

- study of the dynamics of torque developed by a gear hydraulic motor;

- study of the dynamics of power developed by a gear hydraulic motor.

The research objectives include:

- establishing the relationship between the pivot angle of driving gear $\phi_{1}$ and rotation angles $\chi_{1}, \chi_{2}$ of radii $\rho_{1}, \rho_{2}$ connecting the axes of rotation of gears $\mathrm{O}_{1}$ and $\mathrm{O}_{2}$ with

Contact address: Miroslav Bošanský, Slovak University of Technology in Bratislava, Faculty of Mechanical Engineering, Institute of Transport Technology and Designing, Námestie Slobody 17, 812 31, Bratislava 1, Slovakia; e-mail:miroslav.bosansky@stuba.sk 
gearing point $T$, taking into account the slip of involute teeth profiles of the gears, which are relative to each other;

- identification of the patterns of change in the lengths of radii $\rho_{1}, \rho_{2}$ from the parameter $\phi_{1}$.

\section{Results and discussion}

As a geometric interpretation of tooth gearing, the gear teeth are visualized in a form of system of plates $O_{1} A_{1}, O_{2} A_{2}$ $O_{1} T$ and $O_{2} T$ (Figs 1-4). This method was also used by other researchers (Kuleshkov et al., 2010). However, an approach to describe the hydraulic oil flow dependence on the geometric parameters and movement features of gears is used for the first time.

Fig. 1 presents tooth-gearing diagram of a gear hydraulic machine when a new pair of teeth comes into gearing. Fig. 2 presents a gearing diagram at the current moment of time. Fig. 3 shows the gearing diagram when the teeth are in the contact point, and Fig. 4 depicts the gearing diagram when the first pair of teeth comes out of gearing.

While developing the suggested mathematical model, for the reference point purposes, the radius $O M$ was selected to determine the pivot angles of the driving gear elements and the radius $O N$ of the driven gear.

For the driving gear, the point $O_{1}$ is the centre of its rotation. At the same time, for a positive direction, the rotation of the radius is clockwise.

For the driven gear, the point $\mathrm{O}_{2}$ is the centre of its rotation; for the positive direction, the rotation of the radius is taken counter-clockwise.

The reference system is selected in such a way that the pivot angles of the driving and driven gears $\phi_{1}$ and $\phi_{2}$ from the beginning to the end of the tooth gearing (Figs 1-4) will be positive despite the fact that the gears rotate in opposite directions. This is because the volume of hydraulic oil is a scalar quantity and can only be positive.

Here is the description of the proposed geometric model of tooth gearing of a gear hydraulic machine.

In Figs 1-4, the following gear elements and their relationships are presented: $M N$ - teeth gearing line; $P$ - contact point; $\alpha_{w}$ - gearing angle; $r_{a 1}$ - addendum circle radius; $\rho_{1}$,

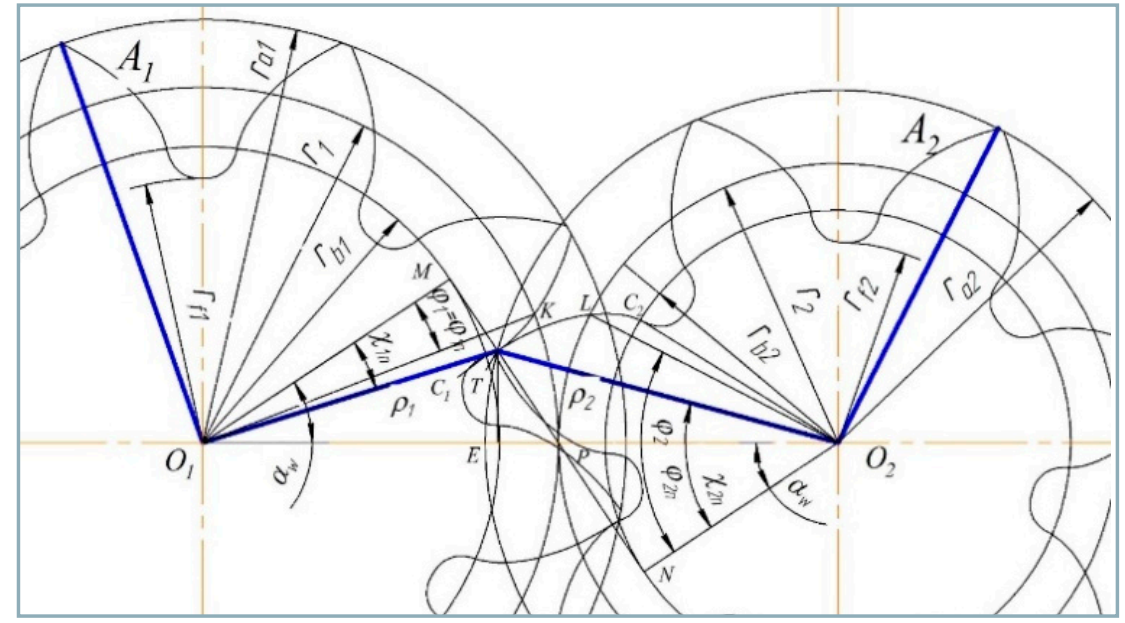

Fig. 1 Diagram at instance of new pair of teeth coming into gearing

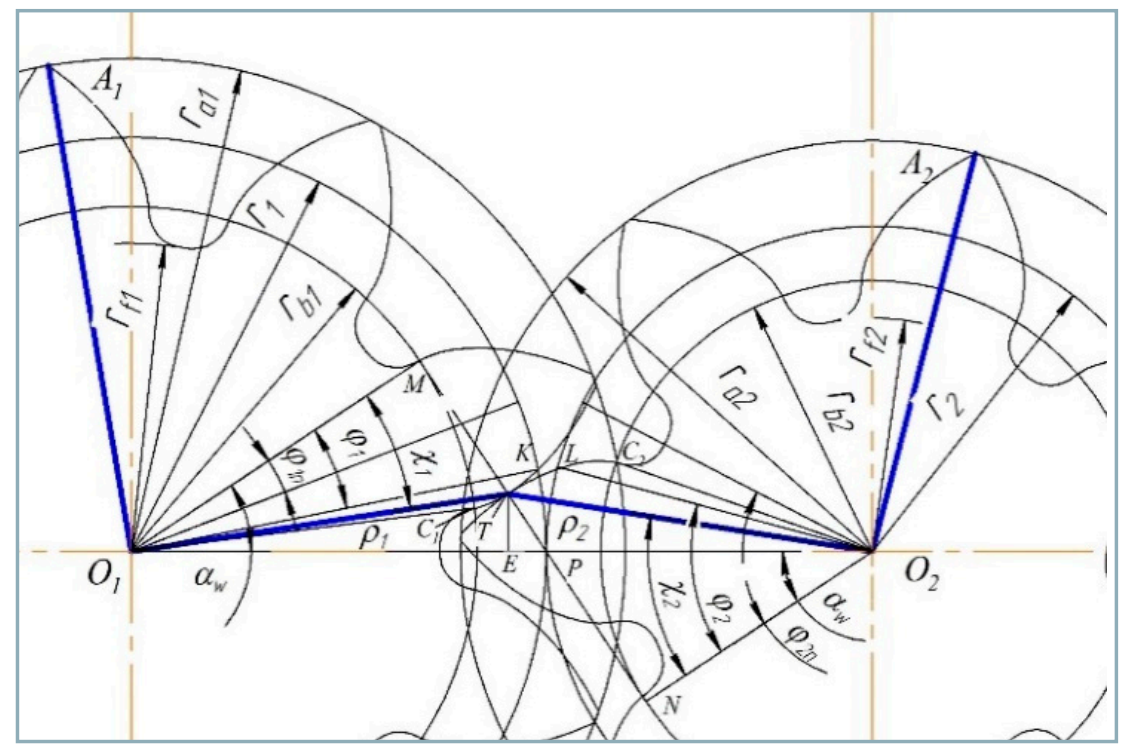

Fig. 2 Diagram of gearing elements position in real time

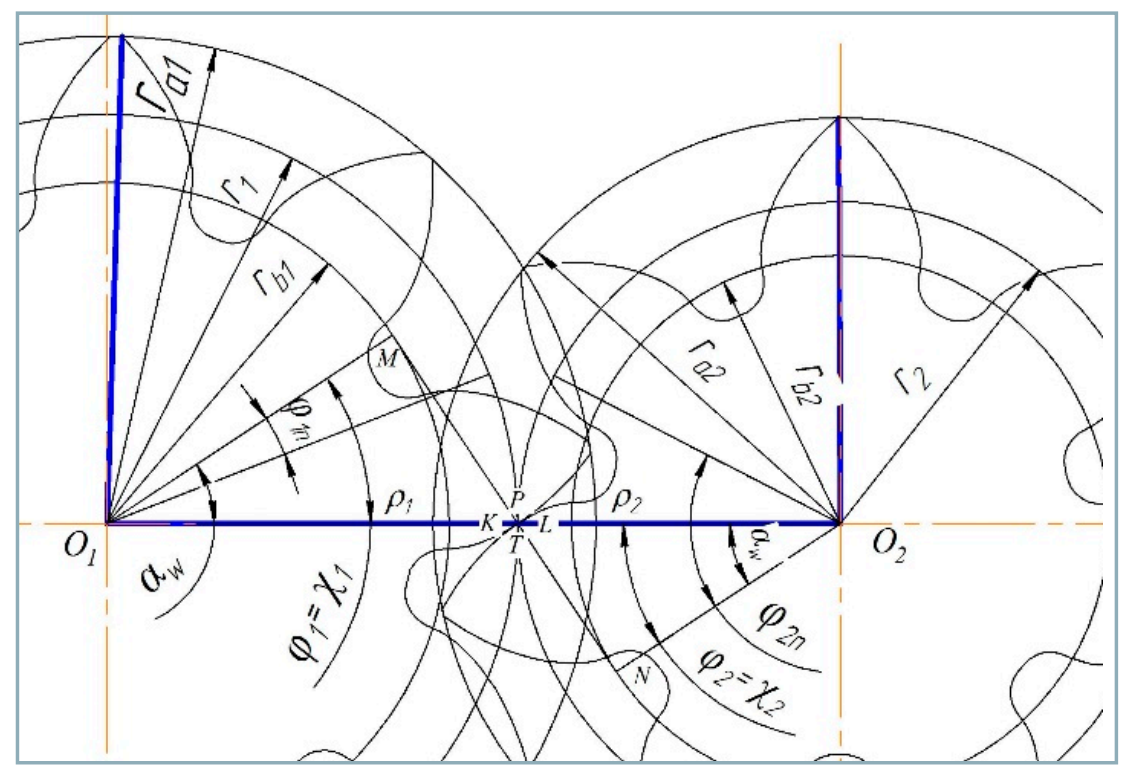

Fig. 3 Diagram of teeth position at contact point 


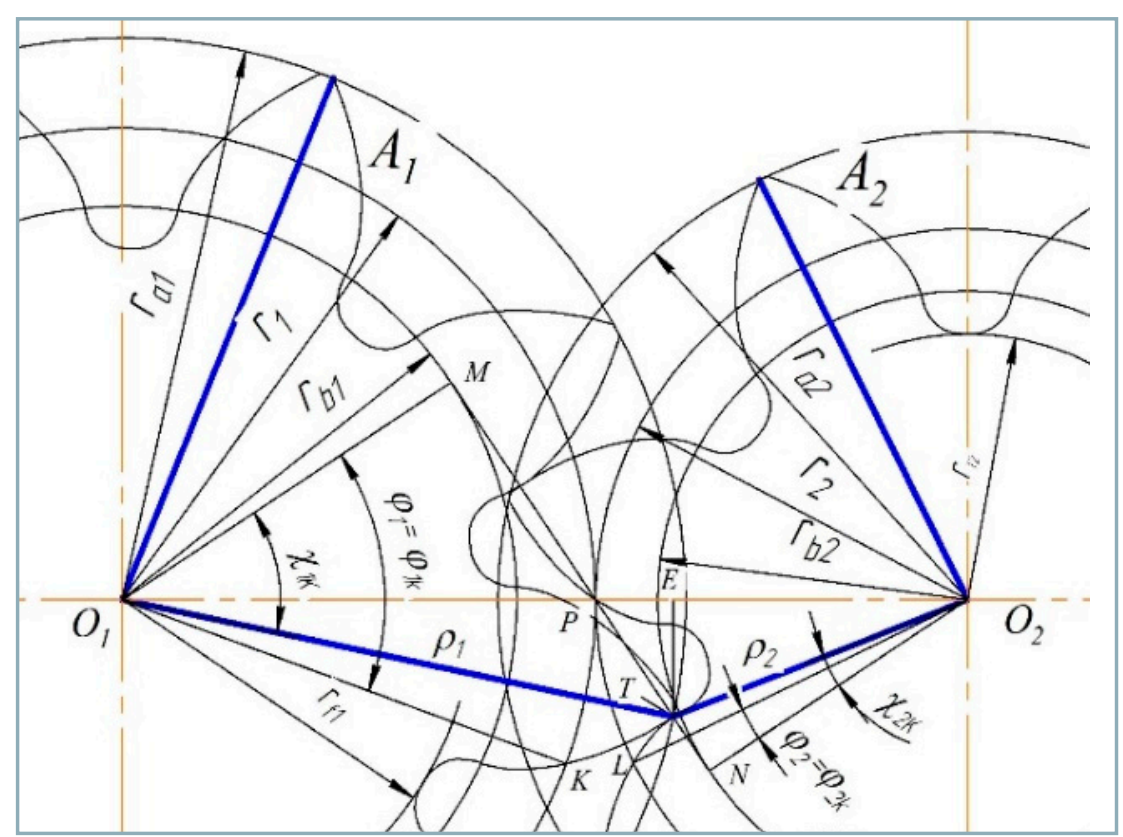

Fig. 4 Diagram at the instance when the first pair of teeth are coming out of gearing

$\rho_{2}$ - radii from the centres of rotation of gears $O_{1}$ and $O_{2}$ to the current point $T$ of the gearing of involute profiles on the gearing line $M N ; x$ - distance from the contact point $P$ to the gearing point of teeth $\mathrm{T} ; \mathrm{O}_{1} \mathrm{C}_{1} ; \mathrm{O}_{2} \mathrm{C}_{2}$ - radii from the centre of rotation of gears to the intersection points of base circles with involute profiles; TE - height of the triangle $\mathrm{O}_{1} \mathrm{O}_{2} T_{;} r_{b 1}, r_{b 2}$ - radii of base circles; $r_{1}, r_{2}$ - radii of pitch circles; $r_{f 1}$, $r_{f 2}$ - radii of dedendum circles; $O_{1} K=r_{1}$, $\mathrm{O}_{2} L=r_{2}$ - radii from the rotation centres of gears rolling over each other; $\phi_{1}, \phi_{2}-$ current pivot angles of the driving and driven gears at measuring reference point from the radii $O M$ for the driving gear and from the radii $O N$ for the driven gear.

There is a dependence between the increase in pivot angle of the driving gear $\Delta \phi_{1}$ and increase in pivot angle of the driven gear $\Delta \phi_{2}$ :

$$
\Delta \phi_{2}=\Delta \phi_{1} / i
$$

where:

$i \quad$ - gear ratio

$i=z_{2} / z_{1}=r_{2} / r_{1}=\omega_{1} / \omega_{2}=n_{1} / n_{2}$

$z_{1}, z_{2}$ - number of teeth of the driving and driven gears

$\phi_{1 n}, \phi_{2 n}$ and $\phi_{1 k}, \phi_{2 k}$ - start and end pivot angles of the driving and driven gears at the beginning and end of tooth gearing by counting from radii $O M$ for the driving gear and from radii $O N$ for the driven gear $\chi_{1 n}, \chi_{2 n}$ and $\chi_{1 k}, \chi_{2 k}-$ start and end pivot angles of the radii $\rho_{1}, \rho_{2}$

It should be taken into account that the driven gear rotates in the opposite direction relative to the driving gear and the angular coordinates of turning of the driven and driving gears have different reference points. This will be taken into consideration later.

Using gearing diagrams presented in Figs 1-4, it is possible to demonstrate the differences in rotational motion of the radii $O_{1} K$ and $O_{2} L$, and the radii $\rho_{1}$ and $\rho_{2}$. As it can be seen in Figs 1-4, the radii $O_{1} K$ and $O_{2} L$ are directly related to the pitch circle and move together with the gears without slip. The radii $\rho_{1}$ and $\rho_{2}$ related to the gearing point also participate in the rotational motion with the slip of involute gear profiles. This is the difference in motion of these radii.

Fig. 1 shows the gearing beginning; the radius $O_{1} K$ is rotated relative to the radius $O_{1} M$ by angle $\phi_{1 n}$, and the radius $\rho_{1}$ is rotated by the angle $\chi_{1 n}$. Accordingly, for the driven gear, the radius $O_{2} L$ is rotated relative to the radius $O_{1} N$ by angle $\phi_{2 n}$, and the radius $\rho_{2}$ is rotated by angle $\chi_{2 n}$. In its rotation, the radius $\rho_{1}$ is ahead of the radius $O_{1} K$ and the difference in the angles of their rotation is $\chi_{1 n}-\phi_{1 n}$. Similarly, the radius $\rho_{2}$ is ahead of the radius $O_{2} L$ in its rotation and the difference in the angles of rotation is $\chi_{2 n}-\phi_{2 n}$.
Further rotation observation of these radii in Fig. 2 indicates that the differences in angles $\chi_{1}-\phi_{1}$ and $\chi_{2}-\phi_{2}$ decreased. Fig. 3 depicts the instance when the points $K$, and $T$ and $L$ and $T$ simultaneously reach the gearing point $P$. In this case, the radii $O_{1} K$ and $\rho_{1}$, and the radii $O_{2} L$ and $\rho_{2}$ coincide and lie on the centre line, and the differences in angles are $\chi_{1}-\phi_{1}=0$ and $\chi_{2}-\phi_{2}=0$. This suggests that the angular rotation velocity of radii $O_{1} \mathrm{~K}$ and $\mathrm{O}_{2} \mathrm{~L}$ is higher than the angular rotation velocity of radii $\rho_{1}$ and $\rho_{2}$, which can be explained by the slip of involute profiles of gear teeth. With further rotation of gears, this trend continues (Fig. 4).

In this context, the aforementioned feature of gear operation of a gear hydraulic machine was not reflected in scientific works (Vacca and Guidetti, 2011). It should be noted that similar approach for developing a mathematical model for the input in gear pump was taken by other researchers. However, the initial assumptions associated with the fact that the angle of rotation of the radii $\rho_{1}$ and $\rho_{2}$ is rigidly connected to the angle of rotation of the driving gear $\phi_{1}$ and the driven gear $\phi_{2}$ are erroneous.

There is a relationship between the angle of rotation of the driving gear $\phi_{1}$ and the angles of rotation of the radii $\rho_{1}$ and $\rho_{2}$. Such a relationship can be obtained based on the definition of involute (Artobolevsky, 1988).

Based on the diagrams (Figs 1-4), for the driving gear, it is possible to give the expression taking into account the concept of the angle involute as follows (Artobolevsky, 1988):

$$
\chi_{1}=\phi_{1}+i n v \alpha_{w}-i n v \chi_{1}
$$

After definition of involute inv $x=$ $\operatorname{tg} x-x$,

after adjusting:

$$
\begin{aligned}
& \chi_{1}=\operatorname{arctg}\left(\phi_{1}+\operatorname{tg} \alpha_{w}-\alpha_{w}\right) \\
& \operatorname{or} \chi_{1}=\operatorname{arctg}\left(\phi_{1}+i n v \alpha_{w}\right)
\end{aligned}
$$

Alternatively:

$$
\begin{gathered}
\phi_{1}=\operatorname{tg} \chi_{1}-\operatorname{tg} \alpha_{w}+\alpha_{w} \\
\operatorname{or} \phi_{1}=\operatorname{tg} \chi_{1}-i n v \alpha_{w}
\end{gathered}
$$

Similarly, the dependence between angles $\chi_{2}$ and $\phi_{2}$ is created:

$$
\chi_{2}=\phi_{2}-i n v \chi_{2}+i n v \alpha_{w}
$$




$$
\begin{gathered}
\chi_{2}=\operatorname{arctg}\left(\phi_{2}+\operatorname{tg} \alpha_{w}-\alpha_{w}\right) \text { or } \chi_{2}=\operatorname{arctg}\left(\phi_{2}+i n v \alpha_{w}\right) \\
\phi_{2}=\operatorname{tg} \chi_{2}-\operatorname{tg} \alpha_{w}+\alpha_{w} \operatorname{or} \phi_{2}=\operatorname{tg} \chi_{2}-i n v \alpha_{w}
\end{gathered}
$$

Dependence of the angle $\chi_{2}$ (4) on the variable $\phi_{2}$ was obtained, which is inconvenient. Let us get the dependence of angle $\chi_{2}$ on the variable $\phi_{1}$, i.e., the dependence $\chi_{2}\left(\phi_{1}\right)$. It is possible to use the concept of gearing ratio. Using Eq. (1) and Figs 1 - 4, one can see that:

$$
\begin{aligned}
& \angle L O_{2} P=\angle K O_{1} P / i \\
& \angle K O_{1} P=\alpha_{w}-\phi_{1} \\
& \phi_{2}=\alpha_{w}+\angle L O_{2} P
\end{aligned}
$$
gets:

Subsequently, taking into account Eqs (8) and (9), one

$$
\phi_{2}\left(\phi_{1}\right)=\alpha_{w}+\left(\alpha_{w}-\phi_{1}\right) / i
$$

for the gearing with the same number of teeth $(i=1)$, leading to:

$$
\phi_{2}\left(\phi_{1}\right)=2 \alpha_{w}-\phi_{1}
$$

Then, the dependence in Eq. (6) can be presented in the following way:

$$
\begin{gathered}
\chi_{2}\left(\phi_{1}\right)=\operatorname{arctg}\left[\left(\alpha_{w}-\phi_{1}\right) / i+\operatorname{tg} \alpha_{w}\right] \\
\chi_{2}\left(\phi_{1}\right)=\operatorname{arctg}\left[\alpha_{w}+\left(\alpha_{w}-\phi_{1}\right) / i+i n v \alpha_{w}\right]
\end{gathered}
$$

For the gears with the same number of teeth $i=1$ and the dependence (13), one gets:

$$
\begin{gathered}
\chi_{2}\left(\phi_{1}\right)=\operatorname{arctg}\left(\alpha_{w}-\phi_{1}+\operatorname{tg} \alpha_{w}\right) \\
\operatorname{or} \chi_{2}\left(\phi_{1}\right)=\operatorname{arctg}\left[2 \alpha_{w}-\phi_{1}+i n v \alpha_{w}\right]
\end{gathered}
$$

The dependences of pivot angles $\chi_{1}, \chi_{2}$ of the radii $\rho_{1}, \rho_{2}$ on the position of gearing point $T$ on the gearing line $M N$ can be useful. This is determined by the distance $x$ of point $T$ from the gearing point $P$. From orthographic $\triangleleft \mathrm{MO}_{1} T$ in Figs 1 and 2, it is possible to write:

$$
\chi_{1}=\operatorname{arctg}\left(M T / r_{b 1}\right)
$$

On the other hand, from orthographic $\triangleleft \mathrm{MO}_{1} P$ (Figs 1 and 2 ), it is also possible to write:

$$
M T=r_{b 1} \operatorname{tg} \alpha_{w}-T P=r_{b 1} \operatorname{tg} \alpha_{w}-x
$$

By substituting the value MT from Eq. (16) in Eq. (15), one gets the expression for the angle $\chi_{1}$ from $x$ :

$$
\chi_{1}=\operatorname{arctg}\left(\left(r_{b 1} \operatorname{tg} \alpha_{w}-x\right) / r_{b 1}\right)
$$

By substituting Eq. (17) in Eq. (4), one gets the dependence of angle $\phi_{1}$ on $x$ :

$$
\phi_{1}=\alpha_{w}-x / r_{b 1}
$$

Furthermore, it is possible to get the dependence of the driven gear pivot angle $\phi_{2}$ on $x$.

From orthographic $\triangleleft \mathrm{NO}_{2} T$ (Fig. 1, 2), it is possible to write $N T=r_{b 2} \operatorname{tg} \alpha_{w}+x$ and:

$$
\operatorname{tg} \chi_{2}=N T / r_{b 2}
$$

By applying Eq. (19), one gets:

$$
\chi_{2}=\operatorname{arctg}\left(N T / r_{b 2}\right)
$$

After adjustments, there is:

$$
\chi_{2}=\operatorname{arctg}\left(\left(r_{b 2} \operatorname{tg} \alpha_{w}+x\right) / r_{b 2}\right)
$$

By substituting Eq. (21) in Eq. (6), one gets the driven gear pivot angle dependence on $x$ :

$$
\phi_{2}=\alpha+x / r_{b 2}
$$

It is possible to get inverse dependences from Eqs (18) and (21):

$$
\begin{aligned}
& x=r_{b 1}\left(\alpha_{w}-\phi_{1}\right) \\
& x=r_{b 2}\left(\phi_{2}-\alpha_{w}\right)
\end{aligned}
$$

Dependence (24) with the help of $\phi_{1}$ :

$$
x=r_{b 2}\left(\alpha_{w}-\phi_{1}\right) / i
$$

The graphs of the studied dependencies were plotted for gears with various parameters and calculated on the basis of pumps NSH-32 UK, which is the most mass-manufactured type in Ukraine. The parameters of the studied NSH-32 UK gearing are presented in Table 1.

Next, the range of argument $\phi_{1}$ was defined. Based on the geometric model of hydraulic oil input shown (Figs 1-4), it can be argued that the variation range of the argument $\phi_{1}$ for the gearing cycle of one pair of teeth can be defined as:

$$
\begin{aligned}
& \phi_{1}=\left[\left(\alpha_{w}-\pi \cdot \varepsilon / z_{1}\right) ;\left(\alpha_{w}+\pi \cdot \varepsilon / z_{1}\right)\right] \\
& \phi_{2}=\left[\left(\alpha_{w}+\pi \cdot \varepsilon / z_{2}\right) ;\left(\alpha_{w}-\pi \cdot \varepsilon / z_{2}\right)\right]
\end{aligned}
$$

where:

$\varepsilon \quad$ - coefficient of teeth overlaps in gearing

The limits of the changes in pivot angles of the driving and driven gears for tooth gearing with different parameters are presented in Table 2 .

The pivot angles of driving and driven gears relative to the radii $\mathrm{O}_{1} \mathrm{M}$ and $\mathrm{O}_{2} \mathrm{~N}$, and alternatively, (Figs $1-4$ ) will have the following form:

$$
\begin{aligned}
& \phi_{1 n}=\alpha_{w}-\pi \cdot \varepsilon / z_{1} \\
& \phi_{1 k}=\alpha_{w}+\pi \cdot \varepsilon / z_{1}
\end{aligned}
$$


Table 1 Technical parameters of tooth gearing in the pumps of NSH-32 UK type

\begin{tabular}{|c|c|c|c|c|c|}
\hline \multirow[t]{2}{*}{ Parameters } & \multicolumn{5}{|c|}{ Parameter values for the number of teeth } \\
\hline & $z_{1}=z_{2}=8$ & $z_{1}=9$ & $z_{2}=7$ & $z_{1}=7$ & $z_{2}=9$ \\
\hline Number of gear teeth $z$ & 8 & $z_{1}=9$ & $z_{2}=7$ & $z_{1}=7$ & $z_{2}=9$ \\
\hline Gearing module $\boldsymbol{m}(\mathrm{mm})$ & \multicolumn{5}{|c|}{5} \\
\hline Angle of base profile $\alpha$ & \multicolumn{5}{|c|}{$20^{\circ}$} \\
\hline Diameter of base circle $d_{b}(\mathrm{~mm})$ & 37.588 & $d b_{1}=42.3$ & $d b_{2}=32.8$ & $d b_{1}=32.38$ & $d b_{2}=42.49$ \\
\hline Addendum diameter $d_{a}(\mathrm{~mm})$ & 55.0 & $d_{a 1}=60$ & $d_{a 1}=50$ & $d_{a 1}=50$ & $d_{a 2}=60$ \\
\hline Angle of tooth gearing $\alpha_{w}$ & \multicolumn{5}{|c|}{$33.355^{\circ}$} \\
\hline Centre distance $\alpha_{w}(\mathrm{~mm})$ & \multicolumn{5}{|c|}{45.0} \\
\hline Width of tooth $S_{a}(\mathrm{~mm})$ & \multicolumn{5}{|c|}{1.0} \\
\hline Length of the bigger axis of the gear pump $G(\mathrm{~mm})$ & \multicolumn{5}{|c|}{100.0} \\
\hline Overlap coefficient of tooth gearing $\varepsilon$ & 1.044 & \multicolumn{2}{|c|}{1.030} & \multicolumn{2}{|c|}{1.032} \\
\hline
\end{tabular}

Table 2 Intervals of pivot angle changes of the driving and driven gears and the radii

\begin{tabular}{|l||c|c|}
\hline \multirow{2}{*}{ Gearing parameters } & \multicolumn{2}{|c|}{ Interval of angle changes } \\
\cline { 2 - 3 } & driving and driven gears & radii $\rho_{1}$ and $\rho_{2}$ \\
\hline \multirow{2}{*}{$\mathbf{z}_{\mathbf{1}, \mathbf{2}}=\mathbf{8}, \varepsilon=\mathbf{1 . 0 4 4}$} & $\phi_{1} \in\left[9.86^{\circ} ; 56.84^{\circ}\right]$ & $\chi_{1} \in\left[13.936^{\circ} ; 46.886^{\circ}\right]$ \\
& $\phi_{2} \in\left[56.84^{\circ} ; 9.86^{\circ}\right]$ & $\chi_{2} \in\left[46.886^{\circ} ; 13.936^{\circ}\right]$ \\
\hline \multirow{2}{*}{$\mathbf{z}_{\mathbf{1}}=\mathbf{9}, \mathbf{z}_{\mathbf{1}}=\mathbf{7}, \varepsilon=\mathbf{1 . 0 3 0}$} & $\phi_{1} \in\left[12.75^{\circ} ; 53.95^{\circ}\right]$ & $\chi_{1} \in\left[16.695^{\circ} ; 45.502^{\circ}\right]$ \\
\hline \multirow{2}{*}{$\mathbf{z}_{\mathbf{1}}=\mathbf{7}, \mathbf{z}=\mathbf{9}, \varepsilon=\mathbf{1 . 0 3 2}$} & $\phi_{2} \in\left[59.836^{\circ} ; 6.864^{\circ}\right]$ & $\chi_{2} \in\left[48.25^{\circ} ; 11.082^{\circ}\right]$ \\
\hline
\end{tabular}

$$
\begin{aligned}
& \phi_{2 n}=\alpha_{w}+\pi \cdot \varepsilon / z_{2} \\
& \phi_{2 k}=\alpha_{w}-\pi \cdot \varepsilon / z_{2}
\end{aligned}
$$

Alternatively:

$$
\begin{aligned}
& \chi_{1 n}=\operatorname{arctg}\left(\operatorname{tg} \alpha_{w}-\pi \cdot \varepsilon / z_{1}\right) \\
& \chi_{1 k}=\operatorname{arctg}\left(\operatorname{tg} \alpha_{w}+\pi \cdot \varepsilon / z_{1}\right) \\
& \chi_{2 n}=\operatorname{arctg}\left(\operatorname{tg} \alpha_{w}+\pi \cdot \varepsilon / z_{2}\right) \\
& \chi_{2 k}=\operatorname{arctg}\left(\operatorname{tg} \alpha_{w}-\pi \cdot \varepsilon / z_{2}\right)
\end{aligned}
$$

Next, the length dependences of radii $\rho_{1}$ and $\rho_{2}$ on the gearing point position on the gearing line $M N$ and on the driving gear rotation angle $\phi$ were found. This position can be determined by the linear coordinate on the gearing line MN (Kuleshkov et al., 2010; Kuleshkov et al., 2009).

Using Figs 1-4, the Pythagorean theorem is applied:

$$
\rho_{1,2}^{2}=\left(r_{b 1,2} \operatorname{tg} \alpha_{w}-x\right)^{2}+r_{b 1,2}^{2}
$$

After certain adjustments, one gets:

$$
\rho_{1}^{2}=\left(r_{b 1} \operatorname{tg} \alpha_{w}-r_{b 1}\left(\alpha_{w}-\phi_{1}\right)\right)^{2}+r_{b 1}^{2}
$$

Similarly, in Figs 1-4, it is possible to see that:

$$
\rho_{2}^{2}=\left(r_{b 2} \operatorname{tg} \alpha_{w}+r_{b 2}\left(\phi_{2}-\alpha_{w}\right)\right)^{2}+r_{b 2}^{2}
$$

Alternatively:

$$
\begin{aligned}
& \rho_{1}=r_{b 1} \sqrt{\left(\operatorname{tg} \alpha_{w}-\alpha_{w}+\phi_{1}\right)^{2}+1} \\
& \rho_{2}=r_{b 2} \sqrt{\left(\operatorname{tg} \alpha_{w}+\phi_{2}-\alpha_{w}\right)^{2}+1}
\end{aligned}
$$

Eq. (40) can be re-written in relation to $\phi_{1}$ taking into account Eq. (14) in the following form:

$$
\rho_{2}=r_{b 2} \sqrt{\left(\operatorname{tg} \alpha_{w}+\left(\alpha_{w}-\phi_{1}\right) / i\right)^{2}+1}
$$

Ultimately, dependences for determining the radii $\rho_{1}$ and $\rho_{2}$ and their rotation angles $\chi_{1}$ and $\chi_{2}$ were obtained. It is often necessary to have dependencies that would reflect the relationship between the radii $\rho_{1}$ and $\rho_{2}$ and the angles of their rotation $\chi_{1}$ and $\chi_{2}$. For these purposes, these dependencies were obtained in a different form.

From the right triangle $\triangleright O_{1} M T$ and triangle $\triangleright \mathrm{O}_{2} N T$, one gets:

$$
\rho_{1,2}=r_{b 1,2} / \cos \chi_{1,2}
$$


Next, it was necessary to define a different form of expressions for the lengths and angles of rotation $\chi_{1}$ and $\chi_{2}$ of the radii $\rho_{1}$ and $\rho_{2}$. Furthermore, by determining the length of the radii $\rho_{1}$ and $\rho_{2}$, it is possible to find the angles of their rotation $\chi_{1}$ and $\chi_{2}$ in the form:

$$
\chi_{1,2}=\arccos \left(r_{b 1,2} / \rho_{1,2}\right)
$$

The obtained expressions for tooth gearings were indicated with the number of teeth $z_{1,2}=8 ; z_{1}=9, z_{2}=7$; and $z_{1}=7, z_{2}=9$.

In certain cases, it is more convenient to use a different reference system, i.e., from the longitudinal axis of the gear

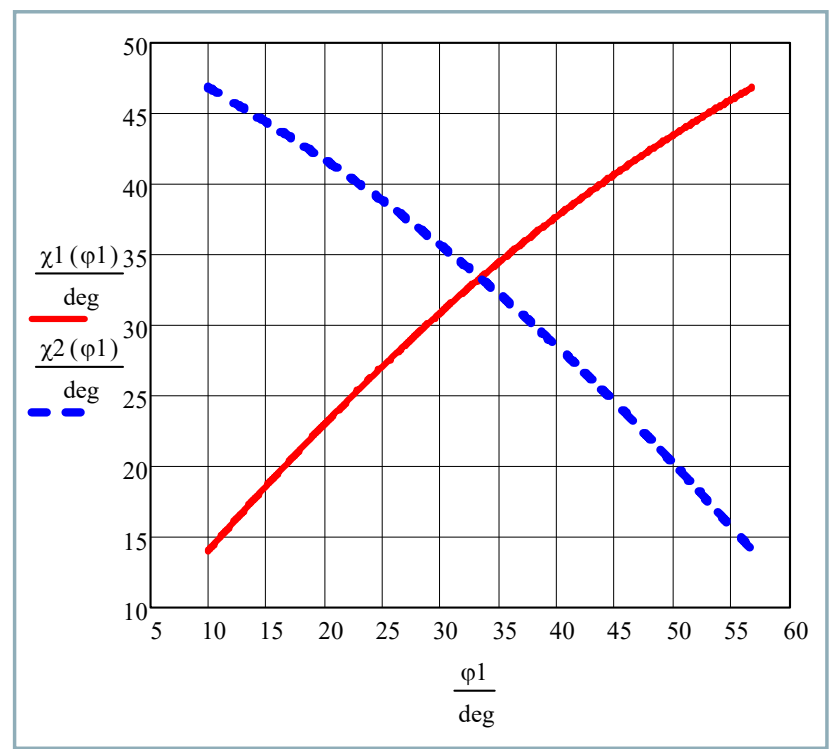

Fig. 5 Dependences of the angles $\chi_{1,2}(\phi)$ of the radius $\rho_{1,2}$ on the driving gear rotation angle $\phi_{1}$ with teeth number $z_{1}=z_{2}=8$

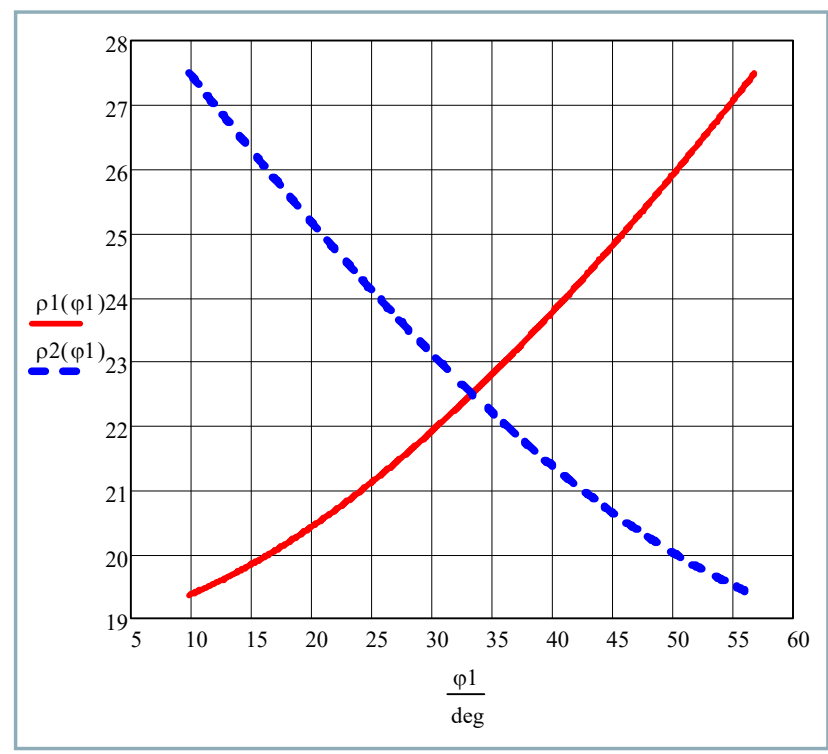

Fig. 6 Dependences of the lengths of radii $\rho_{1}$ and $\rho_{2}$ on the driving gear rotation angle $\phi_{1}$ with the teeth number $z_{1}=z_{2}=8$ hydraulic machine $\mathrm{O}_{1} \mathrm{O}_{2}$. In this case, when the driving gear is rotated clockwise, the angle $\phi_{1}$ will take negative values in the direction from the axis $\mathrm{O}_{1} \mathrm{O}_{2}$ up, and it will take positive values in the direction from the axis down. The dependences of the angles $\chi_{1}$ and $\chi_{2}$ on the parameter $\phi_{1}$ take the following form:

$$
\begin{aligned}
& \chi_{1}=\alpha_{w}-\operatorname{arctg}\left(\operatorname{tg} \alpha_{w}-\phi_{1}\right) \\
& \chi_{2}=\operatorname{arctg}\left(\phi_{1} / i+\operatorname{tg} \alpha_{w}\right)-\alpha_{w}
\end{aligned}
$$

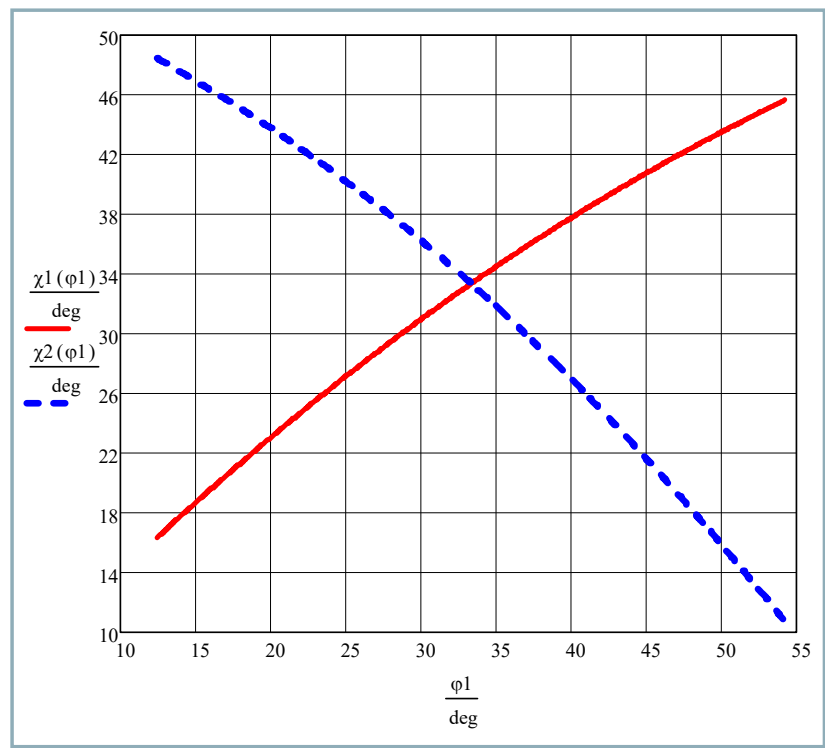

Fig. 7 Dependences of the rotation angles $\chi_{1,2}(\phi)$ of radius $\rho_{1 \text {, }}$ ${ }_{2}$ on the driving gear rotation angle $\phi_{1}$ with teeth number $z_{1}=9, z_{2}=7$

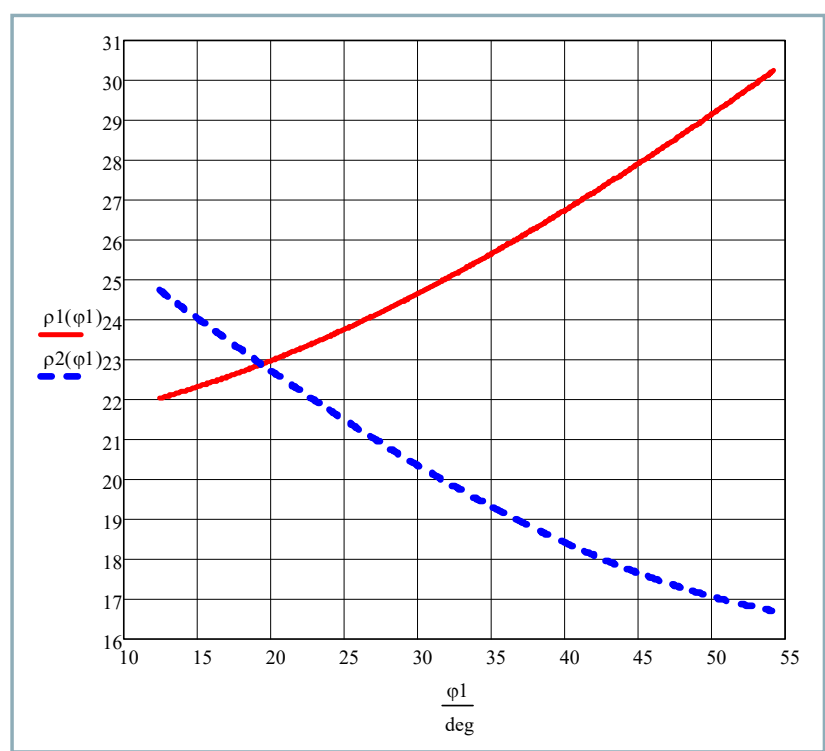

Fig. 8 Dependences of the lengths of radii $\rho_{1,2}$ on the driving gear rotation angle $\phi_{1}$ with teeth number $z_{1}=9, z_{2}=7$ 


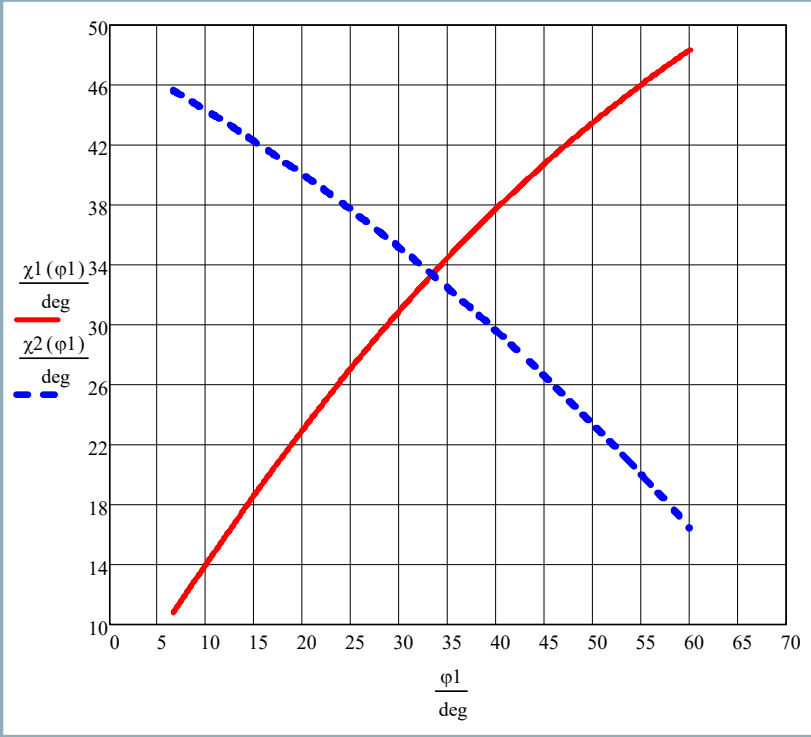

Fig. 9 Dependences of the rotation angles $\chi_{1,2}(\phi)$ of radius $\rho_{1}$ ${ }_{2}$ of the driving gear $\phi_{1}$ with teeth number $z_{1}=7, z_{2}=9$

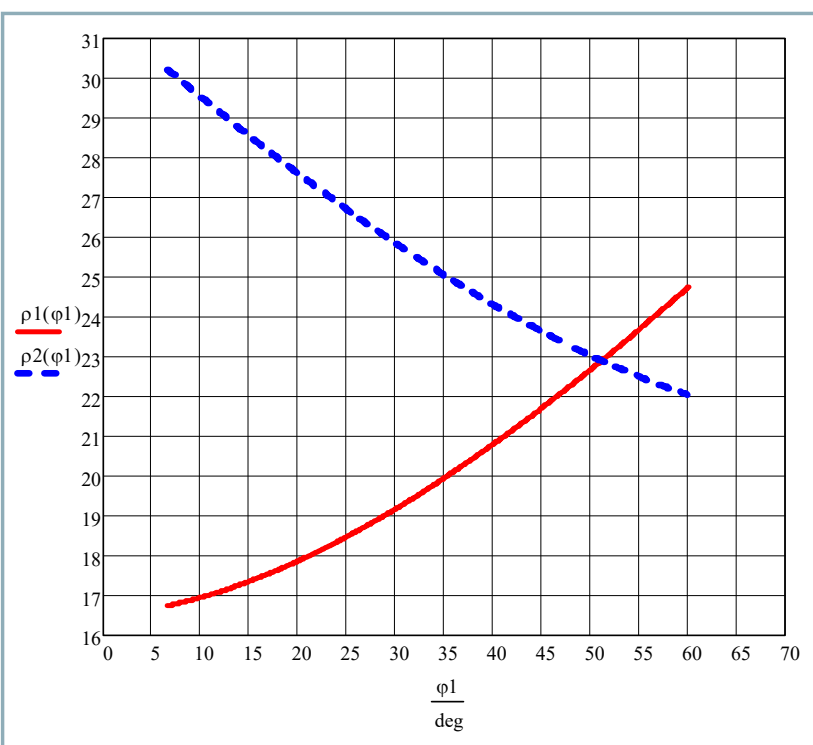

Fig. 10 Dependences of the lengths of radii $\rho_{1,2}$ on the driving gear rotation angle $\phi_{1}$ with teeth number $z_{1}=7, z_{2}=9$

Subsequently, for the dependences of the lengths of the radii $\rho_{1,2}$ on the parameter $\phi_{1}$ :

$$
\begin{gathered}
\rho_{1}=r_{b 1} \sqrt{\left(\operatorname{tg} \alpha_{w}+\phi_{1}\right)^{2}+1} \\
\rho_{2}=r_{b 2} \sqrt{\left(\operatorname{tg} \alpha_{w}-\phi_{1} / i\right)^{2}+1}
\end{gathered}
$$

Corresponding graphical dependencies will have the same form, but the gearing point will be at the point with coordinate 0 (Figs 11, 12).

\section{Conclusion}

1. The source analysis of scientific and technical findings showed that, in the existing models of gear hydraulic

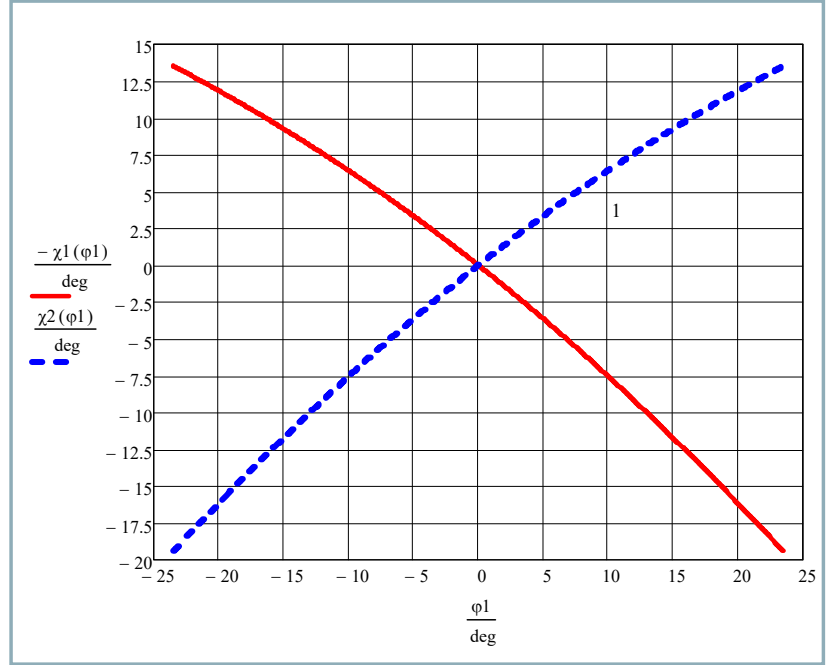

Fig. 11 Dependences of the rotation angles $\chi_{1,2}(\phi)$ of the radius $\rho_{1,2}$ on the driving gear rotation angle $\phi_{1}$ with teeth number $z_{1,2}=8$ in the reference system from the axis $\mathrm{O}_{1} \mathrm{O}_{2}$

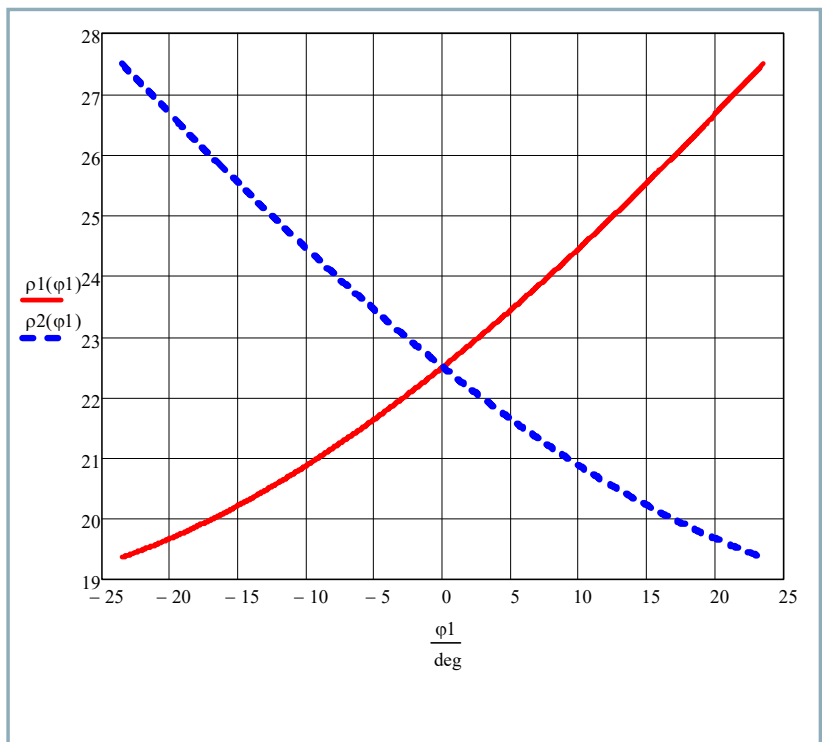

Fig. 12 Dependences of the lengths of radii $\rho_{1,2}$ on the driving gear rotation angle $\phi_{1}$ with teeth number $z_{1,2}=8$ in the reference system from the axis $\mathrm{O}_{1} \mathrm{O}_{2}$

machine working process, the feature of involute gearing is not taken into account. The feature lies in a fact that involute tooth profiles in their movement mutually slip along each other.

2. To study this feature, the task was set and successfully solved to determine the dependences of rotation angles $\chi_{1}$ and $\chi_{2}$ of radii $\rho_{1}$ and $\rho_{2}$ connecting the rotation axes of gears with the gearing point $T$ at the driving gear rotation angle $\phi_{1}$ or the position coordinates of teeth gearing point $T$ on the gearing line. At the same time, the slip of involute gear tooth profiles has been taken into account.

3. The dependences of lengths of radii $\rho_{1}$ and $\rho_{2}$ connecting the rotation axes of gears with the gearing point $T$ at the 
driving gear rotation angle $\phi_{1}$ or the position coordinates of teeth gearing point $T$ on the gearing line were found.

4. The expressions obtained will improve the existing mathematical models of the hydraulic oil movement in gear hydraulic machines, allowing to study a number of processes in hydraulic machines, namely:

- input nature with taking into account the new features in work of gear hydraulic machines;

- features of changes in the cut-off cavity and hydrodynamic processes occurring in it;

- pressure pulsation and hydraulic oil input;

- nature of change in the load on bearings of pump and motor;

- nature of change in combined torque developed by the gear motor;

- nature of change in power developed by the gear hydraulic motor.

\section{References}

ARTOBOLEVSKY, I. I. 1988. Theory of Mechanisms and Machines. Moscow: Nauka Publ., 640 pp. ISBN 978-5020138100. (In Russian: Teoriya mehanizmov i mashin).

CASOLI, P. - VACCA, A. - BERTA, G. L. 2008. Optimization of relevant design parameters of external gear pumps. In Proceedings of the 7th JFPS International Symposium on Fluid Power. Toyama, Japan, Sept. 15-18, 2008. ISBN 4-931070-07-X.

GAMEZ-MONTERO, P. J. - CASTILLA, R. - CODINA, E. 2018 Methodology based on best practice rules to design a newborn trochoidal gear pump. In Proceedings of the Institution of Mechanical Engineers, Part C: Journal of Mechanical Engineering Science, vol. 232, no. 6, pp. 1057-1068.

HUANG, K. J. - CHEN, CH. 2008. Kinematic displacement optimization of external helical gear pumps. In Chung Hua Journal of Science and Engineering, vol. 6, no. 2, pp. 23-28.

IVANOVIC, L. -DEVEDZIC, G. - CUKOVIC, S. - MIRIC, N. 2012. Modeling of the meshing of trochoidal profiles with clearances. In Journal of Mechanical Design, vol. 134, no. 4, pp. 041003-1-041003-9.
KUČERA, M. - ALEŠ, Z. 2017. Morphology analysis of friction particles generated in tractor transmission oils. In Acta Technologica Agriculturae, vol. 20, no. 3, pp. 57-62.

KULESHKOV, Yu. V. - CHERNOVOL, M. I. - RUDENKO, T. V. GUTSUL, V. I. - OSIN, R. A. 2010. Investigation of the behavior of mathematical model of the specific displacement of a gear pump of NSH type from the gearing parameters. In Agricultural Engineering, Industry Engineering, Automation. Collection of scientific works of Kirovohrad National Technical University 2010. Kirovohrad: Kirovohrad National Technical University, pp. 278-290. ISSN 2409-9392.

KULESHKOV, Yu. V. - CHERNOVOL, M. I. - BEZ, O. V. - TITOV, Yu. A. 2009. Gear Pumps with Asymmetric Gearing Line. Theory, Design and Calculation. Monography. Kirovohrad: KOD, 243 pp. ISBN 978-966-1508-19-3.

STRYCZEK, J. - BEDNARCZYK, S. - CODINA, E. - GAMEZ-MONTERO, P. J. - IVANOVIC, L. - MATEJIC, M. 2019. Gears or rotors - three approaches to design of working units of hydraulic machines. In IOP Conference Series: Materials Science and Engineering, vol. 959, pp. 1-13. ISSN 1757-8981.

TKÁČ, Z. - ČORŇÁK, Š. - CVIKLOVIČ, V. - KOSIBA, J. - GLOS, J. JABLONICKÝ, J. - BERNÁT, R. 2017. Research of biodegradable fluid impacts on operation of tractor hydraulic system. In Acta Technologica Agriculturae, vol. 20, no. 2, pp. 42-45.

TULÍK, J. - HUJO, L.. - KOSIBA, J. - JABLONICKÝ J. - JÁNOŠOVÁ, M. 2017. Evaluation of new biodegradable fluid on the basis of accelerated durability test, FTIR and ICP spectroscopy. In Research in Agricultural Engineering, vol. 63, no. 1, pp. 1-9.

VACCA, A. - GUIDETTI, M. 2011. Modelling and experimental validation of external spur gear machines for fluid power applications. In Simulation Modelling Practice and Theory, vol. 19, no. 9, pp. 2007-2031.

WANG, S. - SAKURAI, H.- KASAREKAR, A. 2011. The optimal design in external gear pump and motors. In IEEE/ASME Transactions on Mechatronics, vol. 16, no. 6, pp. 945-952.

ZHOU, H. - DU, R. - XIE, A. - YANG, H. 2017. Investigations of the micro surface shape for the gear shaft/journal - bearing interface in water hydraulic internal gear pumps. In Advances in Mechanical Engineering, vol. 9, no. 11. 